\title{
Magnitude estimates of distance based on object-size
}

At a fixed distance of 1.5 ft., varying sizes of vertical lines or circles were presented to S. Subjects estimated either apparent size or distance based on relative size. Estimates of line height and circle diameter yielded power functions with exponents of 0.97 and 0.98 , respectively. Distance estimates were curvilinearly related to distance predicted from the size/distance ratio. This result is discussed in terms of non-Euclidean space and in relation to the nature of the judgmental task.

The relation between the size of the retinal image $R$, the size of an object $S$, and its distance $D$ is $R=K S / D$ where $K$ is a constant. If the physical size of the object is known, its distance can be inferred from the size of the retinal image. Alternatively, physical size can be inferred if physical distance is known. However, the size of the retinal image itself provides the stimulus only for the ratio of size of object to distance.

While it is commonly asserted that apparent size is a cue to distance (Forgus, 1966; Ogle, 1962), distance estimates based directly on object-size have rarely been reported (Gilinsky, 1955; Holway et al, 1945). More frequently investigators have concentrated on estimates of size as a function of distance in the classical size constancy experiment. The finding that Ss can judge the physical size of objects more or less independently of retinal size is sald to be due to the S's taking distance into account in his perception of size (e.g., Hastorf \& Way, 1952).

The present study investigated the relation between object-size and the estimation of distance when objectsize is the only available cue to distance. Line stimuli (vertical lines or circles) were presented one at a time to Ss at a fixed distance. Some Ss were instructed to imagine that the stimuli remained the same size but varied in distance and were requested to estimate the distance. Others were requested to estimate the apparent size of the stimuli.

\section{Subjects}

Ss were 40 males and 40 females from an introductory psychology class at Indiana University.

\section{Procedure}

The stimuli were seven line circles (or straight lines oriented vertically) drawn in black ink at the center of $12 \times 9 \mathrm{in}$. manila cards, one stimulus per card. The diameters of the circles (height of the lines) were: $0.80,1.20,1.60,2.18,3.13,3.60,4.00 \mathrm{in}$.
Each card was presented to each S 10 times in a sequence that was randomized for each $\mathrm{S}$, except that the first card presented was always the 4.0-in. stimulus. There was a run restriction of no greater than four sequential presentations of the same stimulus. Presentation of stimuli was manual, with a time limit of 5 sec. per exposure.

Within the restriction of equal numbers of each sex, Ss were randomly assigned to one of four judgmental conditions: (1) height of the lines, (2) diameter of the circles, (3) distance based on height of the lines, and (4) distance based on diameter of the circles.

Ss were tested individually and were seated $18 \mathrm{in}$. from the screen where the cards were to be exposed. Their non-preferred eye was covered. For the distance judgments $\mathrm{E}$ read the following instructions: "As an object moves into the distance the image of the object on the retina of the eye gets smaller. Instead of seeing the object as shrinking in size, we see the object remaining the same size, but as being located at a greater distance. The relative size of an object therefore can provide information about distance. I am going to present you with straight lines (circles) drawn on a cardboard sheet. On each occasion I will show you just one line (circle) and you will be required to estimate how far away from you it appears to be. Although the height (diameter) of the line (circle) may differ from occasion to occasion, you are to imagine that the line (circle) remains the same height (diameter) but is merely being located at different distances and you must estimate this distance." In experimental Conditions 1 and 2, Ss were instructed to estimate height and diameter, respectively.

\section{Results and Discussion}

The geometric mean estimates of the seven stimuli were calculated for each $S$ and the geometric mean of these individual means was obtained for all Ss in each condition. By the method of averages (Lewis, 1960 , p. 13), linear functions were obtained for $\log$ geometric mean estimates $(Y)$ against log physical values $(X)$ for both line height and circle diameter. The functions for line height and circle diameter were $Y=0.97 X+0.06$ and $Y=0.98 X+0.05$. Variances of the residuals were 0.000079 and 0.000109 , respectively.

From the height and diameter estimates, and making use of $\mathrm{Ss}$ ' estimates of the $4.0 \mathrm{in}$. stimulus, the apparent distances of the other stimuli were predicted according to the size/distance ratio. Figure 1 shows a plot of $\log$ geometric mean estimates of distance 


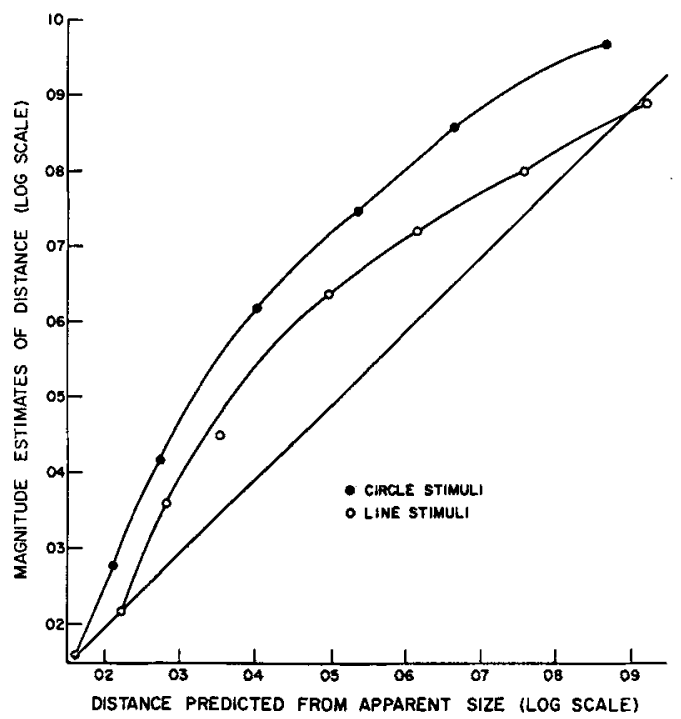

Fig. 1. Log geometric mean estimates of distance plotted against log predicted distance. Predicted distance derived from apparent size estimates on the basis of the size/distance ratio.

against $\log$ distance predicted from apparent size. The diagonal represents the expected relation assuming Ss make optimal use of size information in their distance estimates. However, the relation between log distance estimates and $\log$ predicted distance is curvilinear (curves fitted by inspection).

While apparent size is a cue to distance, it is not related to apparent distance as simply as predicted by the size/distance ratio, coupled with the assumption that subjective space is Euclidean. A number of empirical and theoretical analyses of subjective space have suggested, however, that visual space is hyperbolic (Blank, 1959; Blumenfield, 1913; Hardy, Rand, \& Rittler, 1951).

An attempt was made to fit a hyperbolic function to the present data, but a reduction test using the reciprocals of distance estimates and predicted distance did not give a reasonable approximation to a straight line. In a further endeavour to fit a hyperbolic function, the reduction test for hyperbolas involving an additional constant (as outlined in Lewis, 1960, p. 95) was carried out. As in the earlier case, the reduction test failed to yleld a straight line. Thus, although the results do not support the claim that visual space is hyperbolic, they are congruent with the notion that subjective space is non-Euclidean.

However, before the foregoing interpretation of the results is taken too serlously, it must be noted that estimates of distance based on size essentially require the $S$ to make estimates of the inverse of the size continuum. Stevens and Guirao (1962, 1963) have reported that the estimates of the inverse of a number of perceptual continua do not produce strict reciprocity. Instead, in $\log -\log$ plots there tend to be curvilinear departures from the expected straight line, similar to that obtained in the present experiment. Thus, the present fatlure of size-distance invariance can not be unequivocally interpreted: It may in part be due to subjective visual space being non-Euclidean and/or due to error arising from the necessity to make estimates along an inverse continuum.

\section{References}

Blank, A. A. The Luneberg theory of binocular space perception. In S. Koch (Ed.), Psychology: a study of a science, Vol. 1, New York: McGraw-Hill, 1959.

Blumenfield, $\mathbf{W}$. Untersuchungen über die scheibare Grösse in Sehraums. Z. Psychol. Physiol. Sinnesorgane, 1913, 65, 241.

Forgus, R. J. Perception. New York: McGraw-Hill, 1966.

Gilinsky, A. S. The effect of attitude on the perception of size. Amer. J. Psychol., 1955, 68, 173-192.

Hardy, L. J., Rand, G., \& Rittler, M. C. Investigation of visual space. Arch. Ophthal., 1952. 45, 53.

Hastorf, A. H., \& Way, L. Apparent size with and without distance cues. J. gen. Psychol., 1952, 47, 181-188.

Holway, A. H. et al. Factors influencing the magnitude of range errors in free space and telescopic vision. Harvard Business School, 1945. Quoted in Forgus, R. J. Perception. New York: McGraw-Hill, 1966.

Lewis, D. Quantitative methods in psychology. New York: McGrawHill, 1960.

Ogle, K. N. Perception of distance and of size. In H. Davson (Ed.), The eye. Vol. 4. New York: Academic Press, 1962. Chap. 14.

Stevens, S. S., \& Guirao, M. Loudness, reciprocality, and partition scales. J. Acoust. Soc. Amer., 1962, 34, 1466-1471.

Stevens, S. S., \& Guirao, M. Subjective scaling of length and area and the matching of length to loudness and brightness. J. exp. Psychol., 1963, 66, 177-186.

\section{Note}

1. Present address: Department of Psychology, University of New England, Armidale, N. S. W., Australia.

(Accepted for publication March 7, 1967.) 